\title{
Mild and moderate pre-dialysis chronic kidney disease is associated with increased coronary artery calcium
}

This article was published in the following Dove Press journal:

Vascular Health and Risk Management

I December 201 I

Number of times this article has been viewed

\author{
Sion K Roy \\ Albert Cespedes \\ Dong $\mathrm{Li}$ \\ Tae-Young Choi \\ Matthew J Budoff \\ Division of Cardiology, Department \\ of Medicine, Los Angeles Biomedical \\ Research Center at Harbor-UCLA \\ Medical Center, Torrance, \\ California, USA
}

Background: It is increasingly evident that patients with chronic kidney disease (CKD) are more likely to die from heart disease than kidney failure. This study evaluated whether pre-dialysis $\mathrm{CKD}$ is an independent risk factor for coronary artery calcium (CAC).

Methods: A total of 544 consecutive patients who underwent CAC scoring were analyzed. Eleven patients requiring hemodialysis were excluded. Patients were divided into three groups: normal glomerular filtration rate (GFR) $\left(\right.$ GFR $\left.>90 \mathrm{~mL} / \mathrm{min} / 1.73 \mathrm{~m}^{2}\right)$, mild CKD $(90 \geq$ GFR $\left.>60 \mathrm{~mL} / \mathrm{min} / 1.73 \mathrm{~m}^{2}\right)$, and moderate $\mathrm{CKD}\left(60 \geq \mathrm{GFR}>30 \mathrm{~mL} / \mathrm{min} / 1.73 \mathrm{~m}^{2}\right)$. Continuous and categorical variables were compared using analysis of variance and the $\chi^{2}$ statistic. A multiple logistic regression model was used for detecting the association between total CAC score and GFR. An unadjusted model was used, followed by a second model adjusted for covariates known to be related to CAC. Another multivariable binary logistic model predicting the presence of CAC $(>10)$ was performed and odds of incidence of CAC $(>10)$ were calculated among the three GFR subgroups.

Results: After adjustment for covariates, patients with mild CKD had mean CAC scores 175 points higher than those with the referent normal GFR $(P=0.048)$, while those with moderate $\mathrm{CKD}$ had mean CAC scores 693 points higher than the referent $(P<0.001)$. After adjustment for covariates, patients with mild CKD were found to be 2.2 times more likely ( $95 \%$ confidence interval 1.3-3.7, $P=0.004$ ) and patients with moderate CKD were 6.4 times more likely $(95 \%$ confidence interval $2.9-14.3, P<0.001)$ to have incident CAC compared with the group with normal GFR.

Conclusion: Mild and moderate pre-dialysis CKD are independent risk factors for increased mean and incident CAC.

Keywords: kidney disease, coronary artery disease, atherosclerosis, calcium

\section{Background}

Chronic kidney disease (CKD) has been shown to be an independent risk factor for cardiovascular events and it has become increasingly evident that patients with CKD are more likely to die from cardiovascular disease than kidney failure. ${ }^{1}$ Coronary artery calcium (CAC) score is a marker for atherosclerotic plaque burden and has been shown to be a predictor of incidence of myocardial infarction and death from cardiovascular disease. ${ }^{2}$ Numerous studies have identified an association between end-stage renal disease and $\mathrm{CAC}^{2-4}$ but a link between pre-dialysis $\mathrm{CKD}$ and increased $\mathrm{CAC}$ has not been clearly established. CKD should lead to increased CAC scores secondary to accelerated progression of atherosclerosis, ${ }^{1}$ as well as changes in calcium homeostasis. ${ }^{4}$
Correspondence: Matthew Budoff Los Angeles Biomedical Research Institute at Harbor-UCLA, II 24 W Carson St, Torrance, CA, 0502, USA Tel +I 3102224107

Fax + I 3107829652

Email mbudoff@labiomed.org 
CKD results in accelerated progression of atherosclerosis for many reasons. CKD has been shown to cause both hypertension and dyslipidemia, which are known risk factors for coronary artery disease (CAD). ${ }^{5}$ It causes an increase in blood pressure because of plasma volume expansion, retention of sodium, increased sympathetic activity, increased reninangiotensin-aldosterone axis activity, and the accumulation of endogenous vasoactive substances. ${ }^{6}$ Additionally, there is clear evidence that CKD results in increased LDL and triglycerides, as well as decreased HDL. ${ }^{7}$

Atherosclerosis is an inflammatory condition, as well, and CRP, a marker of systemic inflammation, has been shown to be a surrogate for atherosclerosis and treatment. ${ }^{8} \mathrm{CKD}$ results in increased CRP levels, ${ }^{9}$ which is evidence that CKD results in the increased systemic inflammation associated with atherosclerosis. CKD also alters calcium and phosphorous homeostasis, resulting in increased phosphorous and parathyroid hormone, as well as decreased vitamin D levels. All of this contributes to vascular calcification, including coronary artery calcification. ${ }^{10}$ Finally, CKD also results in increased lipoprotein $\mathrm{A},{ }^{11}$ increased homocysteine, ${ }^{12}$ and anemia, ${ }^{13}$ all of which have been associated with CAD. ${ }^{6}$ The authors of this paper sought to evaluate whether predialysis CKD is an independent risk factor for increased CAC score.

\section{Methods}

\section{Study subjects}

A total of 544 consecutive patients referred to the authors' center (Harbor-UCLA Medical Center) who underwent multidetector computed tomography for CAC assessment were included. Blood draws and detailed surveys regarding symptoms and medical history were performed prior to MDCT scanning. Upon excluding patients undergoing any form of hemodialysis, 533 subjects were available for analysis. No other exclusion criteria were applied. The study was approved by the institutional review board at the authors' institution, and informed consent was obtained from each participant.

Baseline characteristics collected included age, gender, weight, height, body mass index (BMI), self-identified ethnicity (Caucasian, African-American, Hispanic/Latino, Asian, or Other), self-identified lifestyle (subjectively sedentary, active, or stressful), comorbid conditions (hyperlipidemia, hypertension, diabetes), current smoking status, current use of lipid lowering medications, and family history. Reported comorbidities were verified via physical exam, chart review, and laboratory data. Glomerular filtration rate (GFR) was calculated from serum creatinine drawn within 1 month prior to scanning using the simplified Modification of Diet in Renal Disease (MDRD) formula. ${ }^{14}$

\section{MDCT protocol}

All MDCT scans were performed at the center using a 64-multidetector row Lightspeed VCT scanner (GE Healthcare, Little Chalfont, UK). Patients were given beta blockers as needed for a goal heart rate of $<60 \mathrm{bpm}$. The MDCT scanning protocol and interpretation methods for this study were identical to the authors' core computed tomography (CT) reading laboratory function in the Multi-Ethnic Study of Atherosclerosis (MESA) ${ }^{15}$

Calcification was quantified as previously described by Agatston et al. ${ }^{16}$ Total coronary artery calcium score was calculated by the Agatston method as the sum of lesion scores from the four major coronary arteries (left main, left anterior descending, left circumflex, and right coronary arteries). A single experienced interpreter, blinded to the GFR of the participant, interpreted all studies on commercially available software (AccuImage Workstation, AccuImage Diagnostics Corporation, San Mateo, CA) at the time of the study. CAC scores were not re-measured for the purposes of this study.

\section{Statistical analysis}

Patients were divided into three groups: normal GFR $\left(\right.$ GFR $\left.>90 \mathrm{~mL} / \mathrm{min} / 1.73 \mathrm{~m}^{2}\right)$, mild CKD $(90 \geq$ GFR $\left.>60 \mathrm{~mL} / \mathrm{min} / 1.73 \mathrm{~m}^{2}\right)$, and moderate CKD $(60 \geq$ GFR $>30 \mathrm{~mL} / \mathrm{min} / 1.73 \mathrm{~m}^{2}$ ) based on the National Kidney Foundation Kidney Disease Outcomes Quality Initiative practice guidelines for classification. ${ }^{17}$ Continuous variables and categorical variables were compared using analysis of variance and the $\chi^{2}$ statistic, respectively. A multiple logistic regression model was used for detecting the association between total CAC score and GFR in the overall study population. An unadjusted model was used, followed by a second model adjusted for covariates known to be related to $\mathrm{CAC}$, including age, gender, race, BMI, family history, hyperlipidemia, hypertension, diabetes, use of lipid-lowering medication, and current smoking status. The association analysis was performed on the full population, as well as gender subgroups. Since calcium scores have a nonnormal distribution, the median CAC scores are presented in the GFR subgroup comparison.

Another multivariable binary logistic model predicting presence of CAC $(>10)$ was performed and odds of incidence of CAC $(>10)$ were calculated among the three GFR subgroups. This analysis was performed on the full population 
and gender subgroups as well. All data were exported to SAS (v 9.2; SAS Institute, Inc, Cary, NC) for analysis.

\section{Results}

A total of 533 participants were evaluated in the study after eleven subjects were excluded because they were currently undergoing hemodialysis. Of the 533, 240 had GFR in the normal range, 197 subjects had mild CKD, and 96 had moderate CKD. There were significant differences between the groups in terms of gender $(P<0.001)$, race $(P<0.001)$, BMI $(P<0.001)$, lifestyle $(P<0.001)$, smoking status $(P=0.03)$, and incidence of hypertension $(P=0.001)$. The median CAC scores values among the GFR subgroups were 58,151 , and 606 , respectively. Patient demographic data can be found in Table 1.

In the unadjusted analysis, patients with mild CKD $\left(90 \geq\right.$ GFR $\left.\geq 60 \mathrm{~mL} / \mathrm{min} / 1.73 \mathrm{~m}^{2}\right)$ had mean CAC scores 174 points higher than those with the referent normal GFR $\left(\right.$ GFR $\left.>90 \mathrm{~mL} / \mathrm{min} / 1.73 \mathrm{~m}^{2}\right)(P=0.03)$, while patients with moderate CKD $\left(60 \geq\right.$ GFR $\left.>30 \mathrm{~mL} / \mathrm{min} / 1.73 \mathrm{~m}^{2}\right)$ had mean CAC scores 575 points higher than the referent $(P<0.001)$. The significance of these findings held up after adjustment for age, gender, race, BMI, hypertension, lifestyle, and smoking status. After adjustment, patients with mild CKD had mean CAC scores
175 points higher than those with normal GFR $(P=0.048)$, while those with moderate CKD had mean CAC scores 693 points higher than the referent $(P<0.001)$. (See Table 2.)

When men were analyzed as a group, men with moderate CKD had mean CAC scores 834 points higher than those with normal GFR $(P<0.001)$ without adjustment. After adjustment for age, gender, race, BMI, hypertension, lifestyle, and smoking status, men with moderate CKD were found to have mean CAC scores 809 points higher than the referent $(P<0.001)$. Similarly, women with moderate CKD had mean CAC scores 441 points higher than those with normal GFR $(P<0.001)$ without adjustment. After adjustment for the factors just listed, women had mean CAC 544 points higher than those with normal GFR $(P<0.001)$. (See Table 2.)

Without adjustment, in the full population, patients with mild CKD were 1.9 times more likely to have incident CAC (defined as CAC score $>10)(95 \%$ confidence interval [CI] 1.3-2.9, $P=0.002$ ), while patients with moderate CKD were 4.1 times more likely to have incident CAC when compared to the group with normal GFR (95\% CI 2.3-7.8, $P<0.001)$. After adjustment for age, gender, race, BMI, hypertension, lifestyle, and smoking status, patients with mild CKD were found to be 2.2 times more likely (95\% CI 1.3-3.7, $P=0.004)$ and patients with moderate $\mathrm{CKD}$ were

Table I Clinical and demographic characteristics of study population stratified by glomerular filtration rate (GFR) (mL/min per I.73 $\left.\mathrm{m}^{2}\right)$

\begin{tabular}{|c|c|c|c|c|}
\hline & $\begin{array}{l}\text { GFR }>90 \\
n=240\end{array}$ & $\begin{array}{l}90 \geq \text { GFR }>60 \\
\mathrm{n}=197\end{array}$ & $\begin{array}{l}60 \geq \text { GFR }>30 \\
n=96\end{array}$ & $P$-value \\
\hline Age (years) & $55 \pm 11$ & $65 \pm 9$ & $74 \pm 9$ & $<0.001$ \\
\hline Men, n (\%) & $177(73.8)$ & $126(64.0)$ & $49(51.0)$ & $<0.001$ \\
\hline Height (cm) & $174.4 \pm 11.0$ & $170.5 \pm 10.0$ & $164.9 \pm 11.8$ & $<0.001$ \\
\hline Weight (kg) & $93.3 \pm 19.3$ & $78.5 \pm 14.3$ & $67.2 \pm 13.4$ & $<0.001$ \\
\hline BMI $\left(\mathrm{kg} / \mathrm{m}^{2}\right)$ & $30.7 \pm 6.2$ & $27.0 \pm 4.2$ & $24.7 \pm 4.9$ & $<0.001$ \\
\hline Ethnicity, n (\%) & & & & $<0.001$ \\
\hline Caucasian & $156(65.0)$ & $133(67.5)$ & $49(51.0)$ & \\
\hline African-American & $10(4.2)$ & $7(3.6)$ & $7(7.3)$ & \\
\hline Hispanic/latino & $60(25.0)$ & $33(16.8)$ & $17(17.7)$ & \\
\hline Asian & I4 (5.8) & $22(11.2)$ & $21(21.9)$ & \\
\hline Others & $0(0.0)$ & $2(0.9)$ & $2(2.1)$ & \\
\hline Smoking status & $30(12.6)$ & $12(6.2)$ & $5(5.6)$ & 0.03 \\
\hline Lifestyle, n (\%) & & & & $<0.001$ \\
\hline Sedentary & $34(14.2)$ & $33(16.8)$ & $29(30.2)$ & \\
\hline Active & 112 (46.7) & II 8 (60.2) & $48(50.0)$ & \\
\hline Stressful & 7I (29.6) & $22(11.2)$ & $7(7.3)$ & \\
\hline Others & $23(9.5)$ & $23(11.8)$ & $12(12.5)$ & \\
\hline Family history, n (\%) & $139(59.9)$ & $102(53.4)$ & $56(61.5)$ & 0.29 \\
\hline Hyperlipidemia, n (\%) & $133(55.9)$ & $127(64.8)$ & $57(6 \mid .3)$ & 0.16 \\
\hline Lipid lowering medication, $\mathrm{n}$ (\%) & $57(25.0)$ & 61 (31.9) & $29(32.2)$ & 0.22 \\
\hline Hypertension, n (\%) & $100(42.2)$ & $95(48.2)$ & $60(64.5)$ & 0.001 \\
\hline Diabetes, n (\%) & $46(19.2)$ & $32(16.3)$ & $23(25.0)$ & 0.21 \\
\hline Total CAC score median & 58 & $|5|$ & 606 & $<0.001$ \\
\hline
\end{tabular}

Abbreviation: CAC, coronary artery calcium. 
Table 2 Association between glomerular filtration rate (GFR) levels and coronary artery calcium (CAC) score in the full population and gender subgroups

\begin{tabular}{|c|c|c|c|c|c|c|c|c|}
\hline & \multirow{2}{*}{$\begin{array}{l}\text { Number of } \\
\text { subjects }\end{array}$} & \multirow{2}{*}{$\begin{array}{l}\text { Total CACs } \\
\text { median }\end{array}$} & \multicolumn{3}{|c|}{ Unadjusted CACs increase } & \multicolumn{3}{|c|}{ Adjusted CACs increase $^{a}$} \\
\hline & & & $\beta$ (SE) & $95 \% \mathrm{Cl}$ & $P$-value & $\beta$ (SE) & $95 \% \mathrm{Cl}$ & $P$-value \\
\hline \multicolumn{9}{|l|}{ Full population } \\
\hline GFR $>90^{b}$ & 240 & 58 & Referent & & & Referent & & \\
\hline $90 \geq \mathrm{GFR}>60$ & 197 & $|5|$ & $174(8 \mid)$ & 16,333 & 0.03 & $175(88)$ & $2-347$ & 0.048 \\
\hline $60 \geq \mathrm{GFR}>30$ & 96 & 606 & $575(102)$ & 376,774 & $<0.001$ & $693(117)$ & 464,922 & $<0.001$ \\
\hline \multicolumn{9}{|l|}{ Men } \\
\hline GFR $>90^{\mathrm{b}}$ & 177 & 105 & Referent & & & Referent & & \\
\hline $90 \geq \mathrm{GFR}>60$ & 126 & 286 & $238(106)$ & 31,446 & 0.024 & $161(119)$ & $-74,395$ & 0.18 \\
\hline $60 \geq$ GFR $>30$ & 49 & 1230 & $834(147)$ & $547, \mid 121$ & $<0.001$ & $809(|7|)$ & 474,1144 & $<0.001$ \\
\hline \multicolumn{9}{|l|}{ Women } \\
\hline GFR $>90^{\mathrm{b}}$ & 63 & 0 & Referent & & & Referent & & \\
\hline $90 \geq \mathrm{GFR}>60$ & 71 & 15 & $|4|(103)$ & $-62,344$ & 0.17 & $194(114)$ & $-30,418$ & 0.09 \\
\hline $60 \geq \mathrm{GFR}>30$ & 47 & 340 & $44 I(115)$ & 215,667 & $<0.001$ & $544(136)$ & 278,809 & $<0.001$ \\
\hline
\end{tabular}

Notes: aAjusted for age, gender, race, body mass index, hypertension, lifestyle and smoking status; breferent group. Abbreviations: $\mathrm{SE}$, standard error; $\mathrm{Cl}$, confidence interval.

6.4 times more likely $(95 \%$ CI $2.9-14.3, P<0.001)$ to have incident CAC compared with the referent group with normal GFR. (See Table 3.)

Without adjustment, men with moderate CKD were 6.7 times more likely to have incident CAC (95\% CI 2.0-22.6, $P=0.002$ ) compared to men with normal GFR. After adjustment for age, gender, race, BMI, hypertension, lifestyle, and smoking status, men with moderate CKD were 5.4 times more likely to have CAC (95\% CI 1.4-20.6, $P=0.02$ ) compared with the referent. Women with moderate CKD were 6.4 times more likely (95\% CI 2.7-15.3, $P<0.001)$ to have CAC compared to women with normal GFR. After adjustment for age, gender, race,
BMI, hypertension, lifestyle, and smoking status, women with moderate CKD were 6.6 times more likely (95\% CI 2.3-18.7, $P<0.001)$ to have CAC compared with the referent. (See Table 3.)

\section{Discussion}

CAC scores are a reliable screening tool for cardiovascular disease ${ }^{18} \mathrm{CAC}$ scores help predict both incidence of myocardial infarction and death from cardiovascular disease. ${ }^{2}$ In a small cohort, Russo et al previously showed that patients with pre-dialysis CKD have an increased incidence of $\mathrm{CAC}^{19}$ and, in the Dallas Heart Study, Kramer et al showed an association between CKD stages 3-5 and increased CAC. ${ }^{20}$ Most recently,

Table 3 Odds ratios (ORs) for the incidence of coronary artery calcium (CAC) score (CACs > I0) according to glomerular filtration rate (GFR) levels

\begin{tabular}{|c|c|c|c|c|c|c|c|c|}
\hline & Subjects, $\mathbf{n}$ & Incidence of CAC, n (\%) & Unadjusted & & & Adjusted $^{\mathrm{a}}$ & & \\
\hline & & & OR & $95 \% \mathrm{Cl}$ & $P$-value & OR & $95 \% \mathrm{Cl}$ & $P$-value \\
\hline \multicolumn{9}{|l|}{ Full population } \\
\hline $\mathrm{GFR}>90^{\mathrm{b}}$ & 240 & $146(60.8)$ & Referent (I.0) & & & Referent (I.0) & & \\
\hline $90 \geq \mathrm{GFR}>60$ & 197 & $147(74.6)$ & 1.9 & $1.3-2.9$ & 0.002 & 2.2 & I.3-3.7 & 0.004 \\
\hline $60 \geq \mathrm{GFR}>30$ & 96 & $83(86.5)$ & 4.1 & $2.3-7.8$ & $<0.001$ & 6.4 & $2.9-14.3$ & $<0.001$ \\
\hline \multicolumn{9}{|l|}{ Men } \\
\hline GFR $>90^{b}$ & 177 & $123(69.5)$ & Referent (I.0) & & & Referent (I.0) & & \\
\hline $90 \geq \mathrm{GFR}>60$ & 126 & $110(87.3)$ & 3.0 & $1.6-5.6$ & $<0.001$ & 2.3 & $1.1-4.8$ & 0.03 \\
\hline $60 \geq$ GFR $>30$ & 49 & $46(93.9)$ & 6.7 & $2.0-22.6$ & 0.002 & 5.4 & I.4-20.6 & 0.02 \\
\hline \multicolumn{9}{|l|}{ Women } \\
\hline GFR $>90^{b}$ & 63 & $23(36.5)$ & Referent (I.0) & & & Referent (I.0) & & \\
\hline $90 \geq$ GFR $>60$ & 71 & $37(52.1)$ & 1.9 & $0.9-3.8$ & 0.07 & 2.0 & $0.9-4.5$ & 0.10 \\
\hline $60 \geq$ GFR $>30$ & 47 & 37 (78.7) & 6.4 & $2.7-15.3$ & $<0.001$ & 6.6 & $2.3-18.7$ & $<0.00$ I \\
\hline
\end{tabular}

Notes: aAdjusted for age, gender, race, BMI, hypertension, lifestyle and smoking status; ${ }^{b}$ referent group.

Abbreviation: $\mathrm{Cl}$, confidence interval. 
Budoff et al showed a graded relationship between the severity of CKD and CAC. ${ }^{21}$ Haydar et al have further shown that CAC in $\mathrm{CKD}$ is a predictor of obstructive atherosclerosis. ${ }^{22}$

As far as the authors are aware, this present analysis is the first to show a significant association between both mild and moderate pre-dialysis CKD and increased mean CAC, as well as $\mathrm{CAC}$ incidence. The results are quite dramatic but come as no surprise given previous data showing that CKD is an independent risk factor for cardiovascular mortality. ${ }^{1}$ In the authors' full cohort of patients, mild CKD independently predicted an average increase in CAC score of 175, while moderate $\mathrm{CKD}$ independently predicted an increase in CAC score of 693. Patients with a CAC score of 101-299 have an independent increase in relative risk of all-cause mortality of 4.5, while patients with a CAC score of 400-699 have an independent increase of 9.2. ${ }^{23}$ In this study's male cohort, moderate $\mathrm{CKD}$ independently predicted an average increase in CAC score of 834. A CAC score of 834 alone puts any asymptomatic male younger than 75 years old in at least the seventieth percentile for $\mathrm{CAC}$ in his age group. In the female cohort, moderate CKD independently predicted an average CAC score increase of 544. A CAC score of 544 puts any asymptomatic female under the age of 75 years old in at least the eightieth percentile for her age group. ${ }^{24}$

Both the Multi-Ethnic Study of Atherosclerosis $(\mathrm{MESA})^{25}$ and Framingham Offspring Study ${ }^{26}$ failed to demonstrate a similar independent correlation between CKD and CAC. Both these studies only compared patients with GFR $\geq 60 \mathrm{~mL} / \mathrm{min} / 1.73 \mathrm{~m}^{2}$ to patients with GFR $\leq 60 \mathrm{~mL} / \mathrm{min} / 1.73 \mathrm{~m}^{2}$, however. They did not do an analysis comparing patients categorized in three GFR categories as was done in the present study. Additionally, neither of these studies had a sufficiently large enough cohort of patients with CKD: only $9.9 \%$ of patients in the MESA cohort had moderate CKD and only $6.3 \%$ of the Framingham cohort had moderate CKD. The authors' cohort had a robust $18.0 \%$ of patients with moderate CKD in addition to $37.0 \%$ with mild CKD, which explains why the present study showed a significant relationship between CKD and CAC whereas these other studies did not.

The authors' findings provide more impetus that patients with even mild pre-dialysis CKD should be screened and treated more aggressively for heart disease than the average population. This is particularly important in light of studies which have shown that patients with heart disease and concomitant CKD are often treated less aggressively than those with normal kidney function. ${ }^{27,31-33}$ Additionally, there is evidence that more aggressive treatment in these patients does work. In a subanalysis of the Treating to New Targets study, Shepherd et al showed that more aggressive treatment with high-dose atorvastatin led to a cardiovascular risk reduction of $32 \%$ in patients with CKD. ${ }^{31}$ In the Study of Heart and Renal Protection trial, Baigent et al showed that lowering LDL cholesterol with simvastatin and ezitimibe reduced the incidence of major atherosclerotic adverse events in patients with $\mathrm{CKD}{ }^{32}$

Current guidelines say that the goal blood pressure for patients with CKD is $<130 / 80,{ }^{33}$ the goal LDL is $<100 \mathrm{mg} / \mathrm{dL}$, and the goal triglycerides are $<200 \mathrm{mg} / \mathrm{dL} .{ }^{28}$ These goals are largely not being met in clinical practice. ${ }^{29,30}$ Physicians must improve at controlling hypertension and hyperlipidemia, which are major risk factors for cardiovascular disease in patients with even mild CKD. Aggressive treatment to keep calcium and phosphorous levels within the normal range, as well as controlling anemia and diabetes, are important as well. While CKD will inherently accelerate heart disease in our patients, we as physicians must do a better job of slowing down this process so that our patients can live longer and healthier lives.

This paper's major limitation is that it is based upon a single-center, retrospective study. In the future, it would be interesting to perform a prospective, randomized trial to see the impact that strict cardiovascular risk-factor management has on patient outcomes.

\section{Disclosure}

None of the authors has received any funding for this study from any institution. The authors declare no conflicts of interest in this work.

\section{References}

1. Schiffrin EL, Lipman ML, Mann JFE. Chronic kidney disease: effects on the cardiovascular system. Circulation. 2007;116:85-97.

2. Budoff MJ, Gul KM. Expert review on coronary calcium. Vasc Health Risk Manag. 2008;4(2):315-324.

3. Raggi P, Boulay A, Chasan-Taber S, et al. Cardiac calcification in adult hemodialysis patients: a link between end-stage renal disease and cardiovascular disease? J Am Coll Cardiol. 2002;39(4):695-701.

4. McCullough PA, Agarwal M, Agrawal V. Review article: risks of coronary artery calcification in chronic kidney disease: do the same rules apply? Nephrology (Carlton). 2009;14:428-436.

5. Wilson PW, D'Agostino RB, Levy D, Belanger AM, Silbershatz H, Kannel WB. Prediction of coronary heart disease using risk factor categories. Circulation. 1998;97:1837-1847.

6. Baigent C, Burbury K, Wheeler D. Premature cardiovascular disease in chronic renal failure. Lancet. 2000;356:147-152.

7. Vaziri ND. Dyslipidemia of chronic renal failure: the nature, mechanisms, and potential consequences. Am J Physiol Renal Physiol. 2006;290:F262-F272.

8. Blake JK, Ridker PM. C-reactive protein and other inflammatory risk factors in acute coronary syndromes. J Am Coll Cardiol. 2003;42(6) 1142-1143. 
9. Oberg BP, McMenamin E, Lucas FL, et al. Increased prevalence of oxidant stress and inflammation in patients with moderate to severe chronic kidney disease. Kidney Int. 2004;65:1009-1016.

10. Hage FD, Venkataraman R, Zoghbi GJ, Perry GJ, DeMattos AM, Iskandrian AE. The scope of coronary heart disease in patients with chronic kidney disease. J Am Coll Cardiol. 2009;53(23): 2129-2140.

11. Sechi LA, Zingaro L, De Carli S, Sechi G, Catena C, Falleti E. Increased serum lipoprotein (a) levels in patients with early renal failure. Ann Intern Med. 1998;129:457-461.

12. Arnadottir M, Hultberg B, Nilsson-Ehle P, Thysell H. The effect of reduced glomerular filtration rate on plasma total homocysteine concentration. Scand J Clin Lab Invest. 1996;56:41-46.

13. Nangaku M, Eckardt KU. Pathogenesis of renal anemia. Semin Nephrol. 2006;26(4):261-268.

14. Levey AS, Bosch JP, Lewis JB, et al. A more accurate method to estimate glomerular filtration rate from serum creatinine: a new prediction equation. Modification of Diet in Renal Disease Study Group. Ann Intern Med. 1999;130(6):461-470.

15. Carr JJ, Nelson JC, Wong ND, et al. Calcified coronary artery plaque measurement with cardiac ct in population based studies: standardized protocol of multi-ethnic study of atherosclerosis (MESA) and coronary artery risk development in young adults (CARDIA) study. Radiology. 2005;234:35-43.

16. Agatston AS, Janowitz WR, Hildner FJ, Zusmer MR, Viamonte M, Detrano R. Quantification of coronary artery calcium using ultrafast computed tomography. J Am Coll Cardiol. 1990;15:827-832.

17. National Kidney Foundation (NKF) Kidney Disease Outcomes Quality Initiative. KDOQI clinical practice guidelines for chronic kidney disease: evaluation, classification, and stratification; part 4 [web page on the Internet]. New York, NY: NKF; 2002. Available from: http:// www.kidney.org/professionals/kdoqi/guidelines_ckd/p4_class_g1.htm. Accessed April 1, 2011.

18. Ardehali R, Nasir K, Kolandaivelu A, Budoff MJ, Blumenthal RS. Screening patients for subclinical atherosclerosis with non-contrast cardiac CT. Atherosclerosis. 2007;192(2):235-242.

19. Russo D, Palmiero G, De Blasio AP, Balletta MM, Andreucci VE. Coronary artery calcification in patients with CRF not undergoing dialysis. Am J Kidney Dis. 2004;44:1024-1030.

20. Kramer H, Toto R, Peshock R, Cooper R, Victor R. Association between chronic kidney disease and coronary artery calcification: The Dallas Heart Study. J Am Soc Nephrol. 2005;16:507-513.

21. Budoff MJ, Rader DJ, Reilly MP, et al. Relationship of estimated GFR and coronary artery calcification in the CRIC (Chronic Renal Insufficiency Cohort) study. Am J Kidney Dis. Epub July 23, 2011.
22. Haydar AA, Hujairi NMA, Covic AA, Pereira D, Rubens M, Goldsmith DJA. Coronary artery calcification is related to atherosclerosis in chronic renal disease patients: a study comparing EBCT-generated coronary artery calcification scores and coronary angiography. Nephrol Dial Transplant. 2004;19:2307-2312.

23. Budoff MJ, Shaw LJ, Liu ST, et al. Long-term prognosis associated with coronary calcification: observations from a registry of 25,253 patients. J Am Coll Cardiol. 2007;49(18):1860-1870.

24. Mclelland RL, Chung H, Detrano R, Post W, Kronmal RA. Distribution of coronary artery calcium by race, gender, and age: results from the multi-ethnic study of atherosclerosis (MESA). Circulation. 2006;113(1):30-37.

25. Ix JH, Katz R, Kestenbaum B, et al. Association of mild to moderate kidney dysfunction and coronary calcification. J Am Soc Nephrol. 2008;19:579-585.

26. Parikh NI, Hwang SJ, Larson MG, Hoffmann, et al. Indexes of Kidney Function and Coronary Artery and Abdominal Aortic Calcium (from the Framingham Offspring Study). Am J Cardiol. 2008;102:440-443.

27. Shlipak MG, Heidenreich PA, Noguchi H, Chertow GM, Browner WS, McLellan MB. Association of renal insufficiency with treatment and outcomes after myocardial infarction in elderly patients. Ann Intern Med. 2002;137:555-562.

28. NKF Kidney Disease Outcomes Quality Initiative. KDOQI clinical practice guidelines for managing dyslipidemias in chronic kidney disease [web page on the Internet]. New York, NY: NKF; 2003. Available from: http://www.kidney.org/professionals/kdoqi/guidelines_lipids/ index.htm. Accessed November 12, 2010.

29. Peralta CA, Hicks LS, Chertow GM, et al. Control of hypertension in adults with chronic kidney disease in the United States. Hypertension. 2002;45;1119-1124.

30. Stadler SL, Bhardwaja B, Olson KL, Powers JD, Lanese D. An assessment of cholesterol goal attainment in patients with chronic kidney disease. J Clin Lipidol. 2010;4(4):298-304.

31. Shepherd J, Kastelein JJP, Bittner V, et al. Intensive lipid lowering with atorvastatin in patients with coronary heart disease and chronic kidney disease: The TNT (Treating to New Targets) Study. J Am Coll Cardiol. 2008;51:1448-1454.

32. Baigent $\mathrm{C}$, Landray MJ, Reith $\mathrm{C}$, et al. The effects of lowering LDL cholesterol with simvastatin plus ezetimibe in patients with chronic kidney disease (Study of Heart and Renal Protection): a randomised placebo-controlled trial. Lancet. 2011;377(9784):2181-2192.

33. NKF Kidney Disease Outcomes Quality Initiative. KDOQI clinical practice guidelines on hypertension and antihypertensive agents in chronic kidney disease [web page on the Internet]. New York, NY: NKF; 2004. Available from: http://www.kidney.org/professionals/kdoqi/ guidelines_bp/index.htm. Accessed November 12, 2010.
Vascular Health and Risk Management

\section{Publish your work in this journal}

Vascular Health and Risk Management is an international, peerreviewed journal of therapeutics and risk management, focusing on concise rapid reporting of clinical studies on the processes involved in the maintenance of vascular health; the monitoring, prevention and treatment of vascular disease and its sequelae; and the involvement of

\section{Dovepress}

metabolic disorders, particularly diabetes. This journal is indexed on PubMed Central and MedLine. The manuscript management system is completely online and includes a very quick and fair peer-review system, which is all easy to use. Visit http://www.dovepress.com/ testimonials.php to read real quotes from published authors. 